UJMR, Volume 6 Number 1, June, 2021, pp 11 - 17

\title{
Phytochemical Analysis and Antifungal Activity of Ficus Sycomorus L. (Moraceae) Extracts on some Dermatophytic Fungi
}

\author{
Umar, L(iD ${ }^{*}$., Mansir $\mathrm{L}^{1} .,^{1}$ and Sani MG ${ }^{1}$ \\ 1 Department of Biology, Umaru Musa Yar'adua University, Katsina, Nigeria \\ *Corresponding Author E-mail: umar.lawal@umyu.edu.ng \\ Phone Number: +2348034006631
}

\begin{abstract}
Ficus sycomorus $L$ is a large, semi-deciduous spreading savannah tree that belongs to the family (Moraceae) is used by many tribes in the treatments of skin infections. The aim of this study was to carry out phytochemical analysis and antifungal evaluation of $F$. sycomorus $L$. stem and leaf Methanol extract on some dermatophytic fungi. The stem and leaf crude extracts were obtained after drying using maceration and percolation with methanol as the solvent. The extract was subjected to qualitative phytochemical screening as well as GC-MS analysis for the presence of bioactive constituents. The antifungal inhibitory effect of the crude stem and leaf extracts was assessed by agar well diffusion methods. The phytochemical screening revealed that the leaves and stem-bark contained secondary metabolites such as tannins, flavonoids, alkaloids, saponins, reducing sugar and steroid. The GC-MS assay showed that the most prevailing compound in the methanolic stem-bark extract was 2 , 9, Diazabicyclo $(4,4,0)$ decane-3,10 dione, while in the methanolic leaves extract was acetic acid. The anti-dermatophytic assay of the extracts against Microsporum canis and Tricophyton tonsurans showed that the extracts inhibited the fungi with zones of inhibitions ranging from $6.33 \pm 0.47$ to $24.33 \pm 0.47 \mathrm{~mm}$ with the leaf extract exhibiting higher inhibition zones than the stem extract $(p<0.01)$. The study shows that both the stem and leaf methanol extract of Ficus sycomorus $L$ possesses antifungal activity and should be considered as a potential antifungal agent in search of newer agents to address dermatophytic fungal infections
\end{abstract}

Key words: Ficus sycomorus L, Phytochemical/GC-MS Analysis, Antifungal activity

\section{INTRODUCTION}

Ficus sycomorus L. belonging to Moraceae family is known for many vernacular names such as "Baure" in Hausa, "Opoto" in Yaruba, "subula" in Arabic, "Gular" in hindi and in English as wild fig, sycamore fig and common cluster fig (Ahmad et al., 2016). F. sycomorus is a large, semi-deciduous spreading savannah tree, up to 21 (max. 46m), occasionally buttressed. Bark of young stems are pale green with a soft powdery covering while older stems are grey-green, fairly smooth, with scattered grey scales and pale brown patches with heavy latex flow (Harrison et al., 2012).

Ficus sycomorus is used in Nigeria, as extract of fruits, leaves, roost and stem barks to treat various diseases such as skin infections, diarrhea, stomach disorders, liver disease, tuberculosis, and diabetes mellitus. The plant has also been reported to be a potent antimicrobial agent against ciprofloxacin A more recent study by Diso et al., (2020) also recorded higher incidence of dermatophytosis among children with $42.1 \%$ prevalence

\section{UMYU Journal of Microbiology Research}

resistant Salmonella typhi (Dluya et al., 2015). Dermatophytes are fungi capable of parasitizing only keratinized epidermal structures like the skin, hair and nails and are the most common cause of fungal infections worldwide (Shinkafi, 2013). Dermatophytes cause infection of the skin, hair and nails because of their ability to obtained nutrient from keratinized material. Dermatophytic infections were considered major public health problem in many part of the world. The infections are common in the developing countries, and are of particular concern in the tropics and sub-tropics regions because of the humid and warm environment (Shinkafi, 2013). The reported peak incidences of dermatophytic infections occur in school aged children, where it accounts for up to $92.5 \%$ (Shinkafi, 2013). Dermatophytes are susceptible to disinfectants, especially those containing aerosol, iodine and chlorine (Shinkafi, 2013). compared to adult $26.3 \%$.

Tinea capitis is the dermatophytosis of the scalp that is common in children. As human 
contact among children is more frequent between the ages of four and sixteen years than in very early childhood, this age group is similarly at greater risk of contracting infectious diseases (Araya et al., 2021).

The etiological agents of dermatophytosis are generally classified into three genera; Microsporum, Trichophyton and Epidermophyton. Members of the genera Microsporum and Trichophyton usually cause Tinea capitis. The infection may range from mild, almost subclinical, with slight erythema and a few patchy areas of scaling with dull gray hair stumps to a highly inflammatory reaction with folliculitis, kerion formation, and extensive areas of scarring and alopecia. Tinea capitis requires contact with detached hair. Human-to-human transmission usually requires close contact with infected subject or person because dermatophytes are of low infectivity and virulence. In most cases, transmission takes place within families or in situations involving direct contact for example in barbershops (Gupta and Summerbell, 2000).

Documented literature has shown that numerous studies have been conducted to describe the antimicrobial activity of different plant materials, however there still need to continue the search especially bearing the fact that the widespread use of broad-spectrum antibiotic drugs for dermatophytes has led to an increase in the incidence of fungal infections due to development of resistant strains. Studies by Mahmoud (2003) have earlier revealed that the available antifungal agents have a limited effectiveness and lack specificity against the dermatopytes. Moreover, People in the study area have been using medicinal plants in the management of Tinea capitis without any scientific evaluation of the plants. Thus there is need to evaluate the antimicrobial activity of native plants that are being use in the traditional medicine for the treatment of skin infections. The aim of the study was to carry out phytochemical analysis and antifungal evaluation of $F$. sycomorus $L$. stem and leaf Methanol extract on some dermatophytic fungi.

\section{MATERIALS AND METHODS}

Collection Identification and Preparation of Plant Extract

Fresh leaves and stem-bark of $F$. sycomorus were collected, shade dried, pulverizing into a fine powder and stored in a clean airtight plastic container to avert moisture absorption and contamination. Photograph images of collected plant parts were made to help identification process. Final identification was made at the herbarium unit of the Department of Biological Sciences, Umaru Musa Yar'adua University Katsina with voucher number 20170718-08 and the voucher specimen was deposited.

Extraction of stem and leaves of Ficus sycomorus

Extractions of the plant materials were carried out using the procedure described by Shinkafi (2013). Eighty grams of the powdered stem and leaves were extracted by maceration using percolating machine in $500 \mathrm{ml}$ of methanol at room temperature. The extracts were evaporated to dryness; the dried extracts were stored at room temperature until required for further analysis.

Phytochemical analysis

Preliminary phytochemical screening was conducted to detect the bioactive chemicals present in the leaves and stem-bark extracts of $F$. sycomorus. These tests were carried out using standard procedures described by (Trease and Evans, 1989; Sofowora, 1993).

Gas chromatography analysis

Phytochemical assay was carried out using Gas chromatography and mass spectrophotometry. Volatile compound analysis was performed with a gas chromatography system (Aglient 6890 GC) with an Agilent mass spectrometric detector, with a direct capillary interface and fused silica capillary column HP-5 MS $(30 \mathrm{~m} \times 0.32 \mathrm{~mm} \times$ $0.25 \mu \mathrm{m}$ film thickness). Helium was used as the carrier gas at a flow about $1.0 \mathrm{ml} / \mathrm{min}$ pulsed split less. The solvent delay was $3 \mathrm{~min}$. and the injection size was $1.0 \mu \mathrm{l}$. The mass spectrometric detector was operated in an electron impact ionization mode with an ionizing energy of $70 \mathrm{eV}$. Scanning from $\mathrm{m} / \mathrm{z} 50$ to 500 and the ion source temperature was $230^{\circ} \mathrm{C}$. The electron multiplier voltage (EM voltage) was maintained $1250 \mathrm{v}$ above auto tune. The instrument was manually turned using perfluorotributyl amine (PFTBA). Oven temperature program at $45^{\circ} \mathrm{C}(2 \mathrm{~min}), 150^{\circ} \mathrm{C}(5$

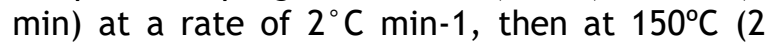
$\min ), 280^{\circ} \mathrm{C}(5 \mathrm{~min})$ at a rate of $8^{\circ} \mathrm{C} \min -1$; split 30:1 during 1.50min, carrier gas He: $1 \mathrm{ml}$ min-1, constant flow; sample volume $1 \mu \mathrm{l}$. Identification was based on comparison of their mass spectra with database of National Institute Standard and Technology (NIST) (Romeh et al., 2013). 


\section{Tinea capitis Sample Collection}

Samples that showed clinical manifestation of dermatophytosis were collected from Qur'anic students popularly known as "Almajirai" in Hausa language, hair from the head were epilated with a brush. They methods described by (Mercy et al., 2014) and (Shinkafi, 2013) were followed for sample collections. The samples were collected after cleaning the affected area with $70 \%$ alcohol using sterile razor blades. The samples were kept in sterilized foil paper, enveloped and transported to the biology laboratory of Umaru Musa Yar'adua University Katsina. Fungal spores resist drying and remain viable for several weeks when stored in paper (Poluri et al., 2015).

\section{Primary Culture of the Samples}

The technique of Wagini et al., (2014) was adapted. Collected samples were inoculated in a Sabouraud Dextrose Agar (SDA) to which chloramphenicol was added to prevent unwanted growth of bacterial contaminants. The plates were then incubated at room temperature for 1-2 days to observe any fungal growth.

\section{Microscopic examination of dermatophytes}

For the microscopic examination of the cultured dermatophytes, lacto-phenol cotton blue was placed on a clean glass slide, and a tuff of fungal filament was picked up from the culture plate using teasing needle. The filaments were transferred to the lacto phenol stain and gently teased and examined under high power objectives at $\times 10$ magnification. The hyphae, spore structure and their arrangement were observed (Wagini et al., 2014).

Preparation of Pure Culture of the Fungal Isolates

A pure culture of Microsporum canis and Trichophyton tonsurans was prepared by subculture of the portion from the primary culture and incubated at room temperature using the procedure described in Wagini et al. (2014).

\section{Preparation of the Test Plant Extracts}

The procedures of (Mercy et al., 2014) and (Wagini et al., 2014) were adopted. The test plants extracts were prepared by serial dilution. To $100 \mathrm{mg}$ of the extract was dissolved in $1 \mathrm{ml}$ of sterile distilled making a concentration of $100 \mathrm{mg} / \mathrm{ml}$. The concentrations of the extracts were made at 100, 50, 25 and $12.5 \mathrm{mg} / \mathrm{ml}$ respectively. The dried samples were stored at room temperature until used in experimental procedures.

Antifungal Assay by Disc Diffusion Method The anti-dermatophytic activities of Ficus sycomorus crude extracts were evaluated by the disc diffusion methods. Spore suspensions of each clinical isolates were aseptically transferred into sterile petriplates. To $20 \mathrm{ml}$ of the cooled molten Sabouraud's dextrose agar was poured in to each plate and the plates were rotated clockwise and anti-clockwise for uniform mixing of fungal spore suspensions wagini (Shahitha et al., 2013). After solidification, wells of approximately $6 \mathrm{~mm}$ in diameter were made on the surface of the agar medium using a sterile cork-borer. Each well was filled with $0.1 \mathrm{ml}$ of the extracts. Clotrimazole was used as control at a concentration of $10 \mathrm{mg} / \mathrm{ml}$. The plates were incubated in triplicate at $28{ }^{\circ} \mathrm{C}$ for 48 hours. The zones of inhibition surrounding the agar wells were measured in $\mathrm{mm}$ (Mercy et al., 2014).

\section{Statistical Analysis}

Data generated were analyzed using analysis of variance (ANOVA) with SPSS version 20.0. Values were significant at $P<0.01$ level. Was further analyzed using DUNNETT Multiple "T" test to study the differences between the experimental (extracts conc.) and control. DUNCAN analysis was computed to differentiate between the sample's mean that are similarly significant.

\section{RESULTS}

Phytochemical Analysis

Preliminary phytochemical investigation of the methanolic leaves and stem-bark extracts of Ficus sycomorus revealed that the leaves and stem-bark contain secondary metabolites such as tannins, flavonoids, alkaloids, saponins, reducing sugar and steroid (which was only found in the leaves extract) while cardiac glycoside absent in both extracts (Table 1) 
Table 1. Phytochemical Constituents of Ficus Sycomorus

\begin{tabular}{lll}
\hline $\begin{array}{l}\text { Secondary } \\
\text { metabolites }\end{array}$ & SBE & LE \\
\hline Tannins & + & + \\
Flavonoids & + & + \\
Cardiac glycoside & - & - \\
Alkaloids & + & + \\
Saponins & + & + \\
Reducing sugar & + & + \\
Steroid & - & + \\
$+=$ Present; - = Absent SBE $=$ stem-bark extract & LE = leaves extract
\end{tabular}

The GC-MS analysis of the methanol stem-bark extracts revealed many peaks with each peak corresponding to a particular phytochemical compound. Some of the compounds identified in the methanol stem-bark extract include; s(+)-1-cyano-2-methyl-azetidine, 2-Butanone,1-Chloro, Ethenamine, N-methylene, 2-Butanone,1-Chloro, Methane, Isocyanato, Propargyl amine, Pyrimidine, 5-methyl-1-Oxide, 1-propene,3,3,3-trifluoro-2-methyl, 2,6-pyrazinediamine, 3Cyclohepten-1-one, 2-Butanamines(s) and 2,9 Diazabicyclo $(4,4,0)$ decane-3,10 dione, cis.

Table 2: Phytocomponents Identified in the Methanolic Stem-Bark Extract Using GC-MS

\begin{tabular}{lllllll}
\hline NO & $\begin{array}{l}\mathrm{RT} \\
(\mathrm{min})\end{array}$ & Name of compound & $\mathrm{MF}$ & $\begin{array}{l}\mathrm{MW} \\
(\mathrm{g} / \mathrm{mol})\end{array}$ & $\begin{array}{l}\text { Peak } \\
\text { area\% }\end{array}$ & Activity \\
\hline 1 & 6.00 & s(+)-1-cyano-2-methyl-azetidine & $\mathrm{C}_{5} \mathrm{H}_{8} \mathrm{~N}_{2}$ & 96.13 & 1.64 & Antimicrobial \\
2 & 6.73 & 2-Butene,2-methyl & $\mathrm{C}_{5} \mathrm{H}_{10}$ & 70.14 & 0.45 & Toxic \\
3 & 7.21 & Ethenamine, N-methylene & $\mathrm{C}_{3} \mathrm{H}_{9} \mathrm{~N}$ & 59.11 & 0.17 & Toxic \\
4 & 10.22 & 2-Butanone,1-Chloro & $\mathrm{C}_{4} \mathrm{H}_{7} \mathrm{C}_{10}$ & 106.55 & 0.39 & Antimicrobial \\
5 & 13.26 & Methane, Isocyanato & $\mathrm{C}_{2} \mathrm{H}_{3} \mathrm{NO}$ & 57.05 & 0.77 & Toxic \\
6 & 13.99 & Propargyl amine & $\mathrm{C}_{3} \mathrm{H}_{5} \mathrm{~N}$ & 55.08 & 0.52 & Antioxidant \\
7 & 34.51 & Pyrimidine,5-methyl-1-Oxide & $\mathrm{C}_{5} \mathrm{H}_{6} \mathrm{~N}_{2} \mathrm{O}$ & 110.113 & 0.45 & Antimicrobial \\
8 & 35.86 & 1-propene,3,3,3-trifluoro-2-methyl & $\mathrm{C}_{4} \mathrm{H}_{5} \mathrm{~F}_{3}$ & 110.08 & 0.12 & No activity \\
9 & 39.93 & 2,6-pyrazinediamine & $\mathrm{C}_{4} \mathrm{H}_{6} \mathrm{~N}_{4}$ & 110.12 & 0.54 & Antimicrobial \\
10 & 41.32 & 3-Cyclohepten-1-one & $\mathrm{C}_{7} \mathrm{H}_{10} \mathrm{O}$ & 110.16 & 0.46 & No activity \\
& & & & & & \\
11 & 43.55 & 2-Butanamines(s) & $\mathrm{C}_{4} \mathrm{H}_{11} \mathrm{~N}$ & 73.14 & 0.28 & Toxic \\
12 & 48.28 & $\begin{array}{l}\text { 2,9 Diazabicyclo (4,4,0) decane-3,10 } \\
\text { dione, cis }\end{array}$ & $\mathrm{C}_{8} \mathrm{H}_{12} \mathrm{~N}_{2} \mathrm{O}_{2}$ & 168.19 & 88.79 & Diuretic \\
\hline
\end{tabular}

$\mathrm{RT}=$ retention time, $\mathrm{MF}=$ molecular formula, $\mathrm{MW}=$ molecular weight

Some of the compounds identified in the methanol leaf extract following GC-MS analysis includes; Methyl vinyl ketone, Propargyl amine, Methane, Isocyanato, Acetic acid,

Cyclopropane,1,2-dimethyl-trans 2-Butanamine(s), 2-Pentene, and Methyl propargyl etheracetic acid (Table 3).

Table 3. Phytocomponents Identified in the Methanolic Leaves Extract Using GC-MS

\begin{tabular}{|c|c|c|c|c|c|c|}
\hline NO & $\begin{array}{l}\text { RT } \\
(\min )\end{array}$ & Name of compound & MF & $\begin{array}{l}\text { MW } \\
(\mathrm{g} / \mathrm{mol})\end{array}$ & $\begin{array}{l}\text { Peak } \\
\text { area\% }\end{array}$ & Activity \\
\hline 1 & 07.97 & Methyl vinyl ketone & $\mathrm{C}_{4} \mathrm{H}_{6} \mathrm{O}$ & 70.09 & 1.97 & Toxic \\
\hline 2 & 11.87 & Propargyl amine & $\mathrm{C}_{3} \mathrm{H}_{5} \mathrm{~N}$ & 55.08 & 3.94 & Antioxidant \\
\hline 3 & 34.54 & Methane, Isocyanato & $\mathrm{C}_{2} \mathrm{H}_{3} \mathrm{NO}$ & 57.05 & 1.17 & Toxic \\
\hline 4 & 40.55 & Acetic acid & $\mathrm{CH}_{3} \mathrm{COOH}$ & 60.05 & 30.21 & Antimicrobial \\
\hline 5 & 42.01 & $\begin{array}{l}\text { Cyclopropane,1,2-dimethyl- } \\
\text { trans }\end{array}$ & $\mathrm{C}_{5} \mathrm{H}_{10}$ & 70.14 & 1.37 & $\begin{array}{l}\text { No activity } \\
\text { reported }\end{array}$ \\
\hline 6 & 43.44 & 2-Butanamine(s) & $\mathrm{C}_{4} \mathrm{H}_{11} \mathrm{~N}$ & 73.14 & 1.6 & Toxic \\
\hline 7 & 43.67 & 2-Pentene, E & $\mathrm{C}_{5} \mathrm{H}_{10}$ & 70.13 & 2.42 & Toxic \\
\hline 8 & 45.2 & Methyl propargyl ether & $\mathrm{C}_{4} \mathrm{H}_{6} \mathrm{O}$ & 70.09 & 1.92 & Toxic \\
\hline
\end{tabular}




\section{UJMR, Volume 6 Number 1, June, 2021, pp 11 - 17 ISSN: 2616 - 0668}

The methanolic leaves and stem-bark extracts of $15.67 \pm 0.94 \mathrm{~mm}$ at $50 \mathrm{mg} / \mathrm{ml}$ the least for the leaves $F$. sycomorus inhibited the fungi with zones of is $8.67 \pm 0.94 \mathrm{~mm}$ at $12.5 \mathrm{mg} / \mathrm{ml}$ The zones of inhibition ranging from $6.33 \pm 0.47$ to inhibition decreased with decrease in the $24.33 \pm 0.47 \mathrm{~mm}$ (Table 4). Microsporum canis concentration of the extracts. Both isolates isolates showed the highest inhibition on the showed that the leaves extract have higher leaves extract $24.33 \pm 0.47 \mathrm{~mm}$ at $100 \mathrm{mg} / \mathrm{ml}$, inhibitory zones while the stem-bark extract $21.33 \pm 0.47 \mathrm{~mm}$ at $50 \mathrm{mg} / \mathrm{ml}$ the least for the leaves exhibited lower zones of inhibition. The zones of is $13.33 \pm 0.47 \mathrm{~mm}$ at $12.5 \mathrm{mg} / \mathrm{ml}$. Trichophyton inhibition are expressed as mean \pm S.D (standard tonsurans isolates showed the highest inhibition on deviation). Significance was obtained at $(\mathrm{p}<0.01)$ the leaves extract $19.00 \pm 0.82 \mathrm{~mm}$ at $100 \mathrm{mg} / \mathrm{ml}$,

Table 4. Anti-Dermatophytic Activity of the Methanolic Leaves and Stem Bark Extracts of $F$. Sycomorus

Zones of inhibition $(\mathrm{mm})$ at different concentrations $(\mathrm{mg} / \mathrm{ml})$

\begin{tabular}{|c|c|c|c|c|c|c|c|}
\hline Extract & Organism & Control & 100 & 50 & 25 & 12.5 & $\begin{array}{l}\text { P. } \\
\text { value }\end{array}$ \\
\hline \multirow{2}{*}{ Leaves } & M. canis & $27.67 \pm 0.94^{a}$ & $24.33 \pm 0.47^{b}$ & $21.33 \pm 0.47^{c}$ & $19.33 \pm 0.94^{d}$ & $" 13.33 \pm 0.47^{e}$ & 0.00 \\
\hline & T. tonsurans & $26.00 \pm 0.82^{a}$ & $" 19.00 \pm 0.82^{b}$ & *15.67士0.94c & $" 14.33 \pm 1.25^{c}$ & $" 8.67 \pm 0.94^{\mathrm{d}}$ & 0.00 \\
\hline \multirow{2}{*}{ Stem } & M. canis & $27.67 \pm 0.94^{a}$ & $20.00 \pm 00^{\mathrm{b}}$ & $18.33 \pm 1.25^{b}$ & $13.00 \pm 00^{c}$ & $8.67 \pm 0.47^{d}$ & 0.00 \\
\hline & T. tonsurans & $26.00 \pm 0.82^{a}$ & $18.33 \pm 0.47^{b}$ & $" 9.33 \pm 0.47^{c}$ & $6.33 \pm 0.47^{d}$ & ${ }^{*} 0.00 \pm 00^{\mathrm{e}}$ & 0.00 \\
\hline
\end{tabular}

Observations are expressed as mean \pm standard deviation (SD). The mean difference is significant at $\mathrm{p}<0.01\left(^{*}\right)=$ Dunnett test (Dunnett test, treat one group as control and compare it against other groups). a,b,c,d,e = Duncan analysis by mean grouping (Duncan analysis grouped mean that have similar significance)

\section{DISCUSSION}

Qualitative preliminary phytochemical investigation of methanolic leaves and stembark extracts of Ficus sycomorus revealed that the leaves and stem-bark contained secondary metabolites such as tannins, flavonoids, alkaloids, saponins, reducing sugar and steroid which was only found in the leaves extract) while cardiac glycoside was absent in both extracts. Some of these secondary metabolites have been previously reported as having antimicrobial activity(Saleh et al., 2015). Findings from this work agreed with the work of Shinkafi (2013) who reported that plants containing tannin flavonoids and saponins are reported to have antimicrobial activity.

The GC-MS analysis of the methanolic leaves and stem-bark extracts revealed many peaks with each peak corresponding to a particular phytochemical compound. The name of compounds, retention time, molecular formula, molecular weight, peak area percent and some of their activities were ascertained. The identified compounds were, generally, reported as having antimicrobial, antioxidant, diuretic and toxic activities. The most prevailing compound in the methanolic stem-bark extract was 2, 9 Diazabicyclo $(4,4,0)$ decane-3,10 dione, cis with peak area percent of $88.79 \%$. While in the methanolic leaves extract was Acetic acid with peak area percent of $30.21 \%$. The antifungal ability of Ficus sycomorus can be attributed to the existence of acetic acid and pyrimidine derivatives \{Pyrimidine, 5-methyle- 1-oxide $(0.45 \%)$, which exhibited antifungal activity as reported by the studies of Kurita \& Koike (1983); Andrews et al. (2017). Also the review of Ferreira \& Kaiser (2012) has shown that the derivatives of pyrazine $\{2,6$ Pyrazinediamine $(0.54 \%)$ \} has antifungal activity the presence of these compounds or there synergy can be attributed to the antifungal activity observed in this plant.

Based on the colony morphology and microscopic observations, two different species Microsporum canis and Trichophyton tonsurans were identified in this study. Microsporum canis grow on the culture medium to form white cotton radiated colony, golden yellow on reverse. Macroconidia are fusoid, thick and rough- walled with curved apex. Trichophyton tonsurans show dark-brown pigmentation with reddish brown to mahogany reverse after 21 days. In microscopy, it reveals numerous micro conidia of varying sizes and shapes.

The methanolic leaves and stem-bark extracts of $F$. sycomorus inhibited the fungi with the zones of inhibition decreasing with decrease in the concentrations of the extracts. Leaves extract showing higher inhibitory zones then the stem-bark extract $(p<0.01)$. This supports the findings of Saleh et al. (2015) who cited leaves extract of $F$. sycomorus as being more effective against $A$. baumannii isolate compared to the stem-bark extract. The largest zone of inhibition was produced against Microsporum canis which indicated that it was more sensitive to the extract than Trichophyton 
tonsurans. The post test (Dunnett test) revealed that there is significant difference between the control and all the extracts regardless of the concentrations $(p<0.01)$.

Among the different concentrations of the extracts used, the least anti-dermatophytic activity was observed with the stem-bark extract against $T$. tonsurans with zone of inhibition of $6.33 \pm 0.4$ at $25 \mathrm{mg} / \mathrm{ml}$ while the highest anti-dermatophytic activity was observed with the leaves extract against $M$. canis with zone of inhibition of $24.33 \pm 0.47$ at $100 \mathrm{mg} / \mathrm{ml}$.

Phytochemicals such as tannins, saponins and flavonoids are reported to be good antimicrobial in a study conducted by (Shinkafi, 2014). These compounds and other compounds identified in the GC-MS such as acetic acid in the leaves extract,s (+)-1-cyano-2-methylazetidine, 2-Butanone, 1-Chloro, Pyrimidine,5methyl-1-Oxide and 2,6-pyrazinediamine in the stem-bark extract could be responsible for the antidermatophytic activity displayed by the leaves and stem-bark extracts of the Ficus

\section{REFERENCES}

Ahmad, A., Dahiru, A., Muhammad, A., Idris, H., \& Gautam, K. (2016). Phytochemical Screening and Antimicrobial Activity of Ficus sycomorus Extracts of the Stem Bark and Leaves on Some Pathogenic Microorganisms. American Chemical Science Journal, 13(3), 1-5.

Andrews, B., Komathi, K., \& Mohan, S. (2017). Synthesis and comparing the antibacterial activities of pyrimidine derivatives. Journal of Chemical Sciences, 129(3), 335-341.

Araya, S., Abuye, M., \& Negesso, A. E. (2021). Epidemiological Characterization of Dermatomycosis in Ethiopia. Clinical, Cosmetic and Investigational Dermatology, 14, 83.

Ferreira, S. B., \& Kaiser, C. R. (2012). Pyrazine derivatives: a patent review (2008present). Expert opinion on therapeutic patents, 22(9), 1033-1051.

Diso, S. U., Ja'afar, S., Mu'azu, L., Abdallah, M. S., \& Ali, M (2020). Isolation and Characterization of Some Fungi Associated with Superficial Fungal Infections. Journal of Dermatology, Volume 5, Issue 1, 2020, PP 12-16

Dluya, T., Daniel, D., \& Gaiuson, Y. (2015). Comparative biochemical evaluation of leaf extracts of Ficus sycomorus and Piliostigma thonningii plant. Journal of Medicinal Plant Studies, 3(5), 32-37.

Gupta, A. K., \& Summerbell, R. C. (2000). sycomorus in this research. Finally, the study ascertained and confirmed that $F$. sycomorus has potential antidermatophytic properties although the plant contains some toxic compounds.

\section{CONCLUSION}

The current study revealed that $F$. sycomorus extracts from various concentrations of methanolic leaves and stem extracts demonstrated anti-dermatophytic activity against Microsporum canis and Trichophyton tonsurans. The methanolic leaves extract possessed more antidermatophytic activity than the methanolic stem-bark extract. Some of the compounds identified in the plant extract include acetic acid, s (+)-1-cyano-2methyl-azetidine, 2-Butanone, 1-Chloro, Pyrimidine,5-methyl-1-Oxide and 2,6pyrazinediamine. However, further analysis is required for the isolation of bioactive molecules from the plant that may have a broad spectrum of pharmacological activities and toxicity evaluation of the plant extract.

Tinea capitis. Medical Mycology, 38(4), 255-287.

Harrison, R. D., Rønsted, N., Xu, L., Rasplus, J. Y., \& Cruaud, A. (2012). Evolution of fruit traits in Ficus subgenus Sycomorus (Moraceae): to what extent do frugivores determine seed dispersal mode?. Plos one, 7(6), e38432.

Kurita, N., \& Koike, S. (1983). Synergistic antimicrobial effect of ethanol, sodium chloride, acetic acid and essential oil components. Agricultural and biological chemistry, 47(1), 67-75

Mahmoud, Y. A. G. (2003). In vitro evaluation of anti-dermatophytic activity of Egyptian Bee propolis in combination with plant essential oils in sheep hoof plate: an experimental model. Mycobiology, 31(2), 99-104.

Mercy, K. A., Ijeoma, I., \& Emmanuel, K. J. (2014). Anti-dermatophytic Activity of garlic ( Allium sativum ) extracts on some Dermatophytic fungi. International Letters of Natural Sciences, 19, 34-40.

Poluri, L., Indugula, J., \& Kondapaneni, S. (2015). Clinicomycological study of dermatophytosis in South India. Journal of Laboratory Physicians, 7(2), 84.

Romeh, \& A, A. (2013). Phytochemicals from Ficus sycomorus L. leaves act as insecticides and acaricides. African Journal of Agricultural Research, 8(27), 3571-3579. 
Saleh, B., Hammoud, R., \& Al-Mariri, A. (2015). Antimicrobial activity of Ficus sycomorus L. (Moraceae) leaf and stembark extracts against multidrug resistant human pathogens. Herba Polonica, 61(1), 39-49.

Sule, W. F., Okonko, I. O., Omo-Ogun, S., Nwanze, J. C., Ojezele, M. O., Ojezele, O. J., ... \& Olaonipekun, T. O. (2011). Phytochemical properties and in-vitro antifungal activity of Senna alata Linn. crude stem bark extract. Journal of medicinal plants research, 5(2), 176183.

Shahitha, S., Saranya, M., \& Poornima, K. (2013). Isolation and identification of dermatophytes from clinical samples and antidermatophytic activity of Lawsonia inermis (Henna plant). Int. journal of pharmaceutical and chemical sciences, 2(2), 1014-17.

Sofowora, A. (1993). Screening plants for bioactive agents. Medicinal plants and traditional medicinal in Africa, 2, 134156.
Shinkafi, S. A. (2013). Antidermatophytic activities, Phytochemical screening and Chromatographic studies of Pergularia tomentosa $\mathrm{L}$. and Mitracarpus scaber Zucc. (Leaves) Used in the Treatment of Dermatophytoses. Research Paper, 4(January), 29-37.

Shinkafi, S. A. (2014). Phytochemical analysis and chromatographic studies of Pergularia tomentosa L. and Mitracarpus scaber Zucc. Microbiology Research Journal International, 550559.

Trease, G.E. and Evans, W.C. (1989). Pharmacognosy, 13th ed., Bailliere Tindall: London, UK. pp. 683-684.

Wagini, N. H., Abbas, M. S., Soliman, A. S., Hanafy, Y. A., \& Badawy, E. M. (2014). In vitro and in vivo anti dermatophytes activity of Lawsonia inermis L . ( henna ) leaves against ringworm and its etiological agents, Clinical and Experimental Medicine 2(3), 51-58. 